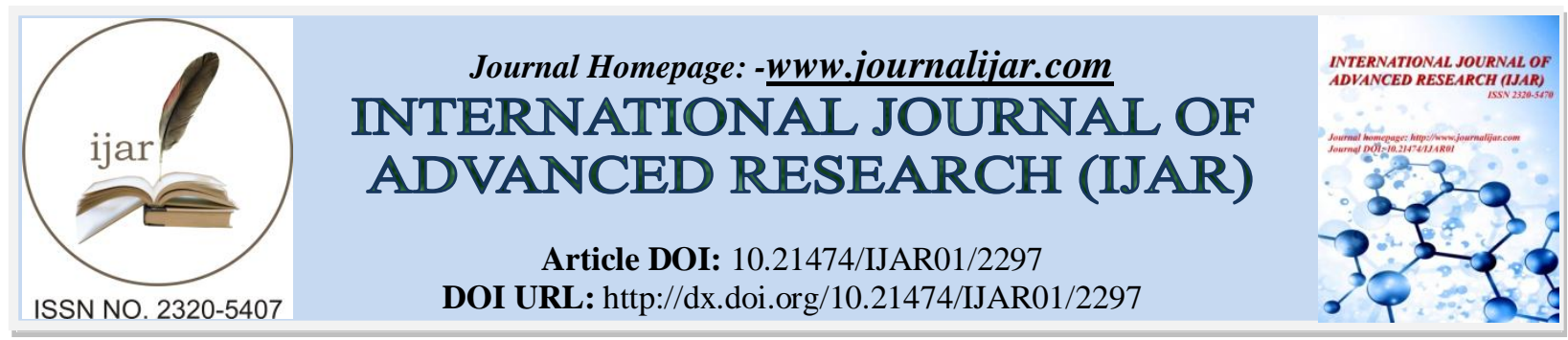

RESEARCH ARTICLE

\title{
BIOLOGICAL EFFECTS OF TOPICAL HYALURONIC ACID ON ORAL ULCER'S HEALING IN RATS RECEIVING METHOTREXATE.
}

\author{
K. M. Elsherbiny ${ }^{1}$, N. N. Abdel Salam ${ }^{2}$ and F. M. Ibrahim ${ }^{3}$. \\ 1. Department of Dentistry, Mansoura University, Egypt. \\ 2. Assistant Professor of Oral Biology, Faculty of Dentistry, Mansoura University. \\ 3. Professor of Oral Biology, Faculty of Dentistry, Mansoura University.
}

\section{Manuscript Info}

Manuscript History

Received: 29 September 2016

Final Accepted: 30 October 2016

Published: November 2016

Key words:-

Oral ulcer, Hyaluronic acid (HA),

Methotrexate (MTX).

\begin{abstract}
This study was conducted to evaluate the effects of topical application of hyaluronic acid on oral ulcer of rats receiving methotrexate. Forty five male albino rats wgt 200-250 were selected in the study and divided into three groups: I) control group, II) methotrxate group without any treatment, III) methotrexate group+ Hyaluronic acid. Ulcer was inducted after one week of methotrexate injection in groups (II and III). The five rats from each group were sacrificed after 4 days, one week and two weeks consequently. Then the ulcers were taken for histological and ultra structural examination. At the end of this study the hyaluronic acid group showed faster healing of oral ulcer than the control group.
\end{abstract}

Copy Right, IJAR, 2016,. All rights reserved.

\section{Introduction:-}

Oral ulcer is damage to both epithelium and lamina propria, sometimes it appears clinically by swelling caused by edema or proliferation in the surrounding tissue. Ulcers are common in those treated with cytotoxic drugs particularly methotrexate (Scully, stephen . Porter 2003). Wound healing is a complex process that occurs in overlapping phases: inflammation, proliferation, angiogenesis, epidermal restoration, wound contraction and remodeling (Shaw, Martin 2009).

Methotrexate (MTX) is an immune modulating drug used in treatment of various neoplastic diseases when taken at high dose including leukemia, non-Hodgkinlymphoma, and at lower doses in control of chronic inflammatory disorder such as rheumatoid arthritis and psoriasis Deeming, Collingwood, Pemberton 2005. Hyaluronic acid (HA): HA is a naturally occurring linear polysaccharide of extracellular matrix of connective tissue, synovial fluid, and other tissues. It has anti-inflammatory, anti-edematous, and anti-bacterial effects for the treatment of periodontal disease, its main function includes tissue healing by activation and moderation of inflammatory response, promotion of cell proliferation, migration, and angiogenesis it also promotes re-epithelization via proliferation of basal keratinocytesKapoor P et al., 2011.HA is also anhygroscopicmacromolecule that its solutions are highly osmotic which enables to control hydration of the tissue in oral mucosaduring periods of inflammatory process or response to tissue injury which resulting in ulcer formation.

\section{Material and methods:-}




\section{Animals:-}

In this study, 45 white albino rats (200-250 gm body weight) were housed in Mansoura experimental research center, faculty of medicine, Mansoura university, according to the ethical and animal care guidelines of Mansoura university. They were divided into three groups(15 animals each):

\section{* Group I(Control group):}

The rats of this group received ulcer without any treatment.

\section{* Group II (MTX group):}

The rats of this group received I.P injection MTX (10mg/kg/week)AIRefai etal., 2014.

* Group III (MTX + Hyaluronic acid):

The rats of this group received $\mathrm{MTX}(10 \mathrm{mg} / \mathrm{kg} / \mathrm{week})$ and hyaluronic acid topicallyadminstrated (240mg/100g)AlBayaty,Mahmood 2012 twice daily.

\section{* Ulcer induction:}

Ulcer was done at every animal's cheek mucosa bilaterally by using biopsy punch to ensure that all ulcers had the same size. The punch is circular in shape about $4 \mathrm{~mm}$ in diameter.

\section{* Biobsy collection:}

After ulcer induction, specimens were obtained from each animal after 4days, 7days, and 14 days; specimen of right sides of cheek of each animal were removed and immediately fixed with $10 \%$ formalin solution.Specimens of left sides of each animal cheek were put in glutaraldehyde fixative solution.

\section{* Sections of specimens were prepared for:}

1- Heamatoxyline and Eosin stain: routine histological examination.

2- Transmition electron microscope: specimens will be processed for ultrastructural examination.

\section{Computer Assisted digital image analysis:-}

Slides were photographed using Olympus ${ }^{\circledR}$ digital camera installed on Olympus ${ }^{\circledR}$ microscope with $1 / 2$ X photo adaptor, using $40 \mathrm{X}$ objective. The result images were analyzed on Intel ${ }^{\circledR} \mathrm{Core}^{\mathrm{I}} 3^{\circledR}$ based computer using VideoTest Morphology ${ }^{\mathscr{\Theta}}$ software (Russia) with a specific built-in routine for area, \% area measurement and object counting.

\section{Statistical analysis:-}

Data were tabulated, coded then analyzed using the computer program SPSS (Statistical package for social science) version 17.0. Data were expressed as Mean and Standard deviation ( \pm SD). The statistical comparison between the different groups, the significance of difference was tested using one of the following tests:

1- Analysis of variance (One way ANOVA): Used to compare between more than two groups of numerical (parametric) data followed by post-hoc tukey.

2- Repeated ANOVA (analysis of variance):Used to compare between more than two related groups of numerical (parametric) data followed by post-hoc LSD.

A $P$ value $<0.05$ was considered statistically significant $(\mathrm{S})$.

\section{Results:-}

* Histological results:-

1- Haematoxylin and Eosin stain:-

After 4 days in group I there were loss of cell attachment, mitotic activity was observed. As while as in group II and III the ulcer area was filled with granulation tissue which showing infilteration of inflammatory cells and dilated blood vessels.

After 7 days in group II The ulcer size was larger than its size in control groupI, granulation tissue showed infiltration of inflammatory cells and collagen formation. But in group III the ulcer size was smaller than it's size in group II, the epithelium showed further migration into the ulcer bed,also there are more infiltration of inflammatory cells, and collagen formation showed in granulation tissue.

After 14 days in group III, the epithelium showed reorganization and stratification, with irregular basement membrane. Lamina propria showed organized collagen bundles and fibroblast but in group II lamina propria showed unoraganized collagen fibers, large number of fibroblast, newly formed blood vessels in between. 
2- Ultrastructural results:

Transmission electron microscope analysis:

After 4 days ultra-structural analysis showed swollen mitochondria, no desmosomal attachment, and high intercellular spaces in the epithelium and also there was irregularly arranged and loosly packed collagen fibers in group I,II but in group III there was moderate widening in intercellular spaces with less destructed basal lamina, and regularly arranged collagen fibers.

After 7 days there was moderate widening intercellular spaces with less detructeddesmosomal junction and partially regained basal lamina with more packed and better aligned collagen fibers in group I and also in group II.But in group III there was mild widening with varuable regaining of desmosomal junction with nearly intact basal lamina and more densly packed collagen fibers.

After 14 days in group I there was mild widening of intercellular spaces with valuable regaining of epithelial cells and desmosomal junction, nearly intact basal lamina with more densly packed collagen fibers as will as group II, but in group III there was normal intercellular spaces with intact desmosomal junction and euchromatic nucleus and also there was intact basal lamina with regular and packed collagen fibers.

\section{Discussion:-}

The main function of (HA) includes tissue healing including activation and moderation of inflammatory response, promotion of cell proliferation, migration, and angiogenesis it also promotesre-epithelization via proliferation of basal keratinocytes (Kapoor etal., 2011).

In Hematoxylin and eosin result in this study, samples of $14^{\text {th }}$ day post ulceration showed complete healing in all studied groups.

This result is in accordance with Karavanaetal.,2011who reported that oral mucosal ulceration in the animal model showed complete healing on the $12^{\text {th }}$ day post ulceration.

In the present study, group II which received MTX showed ulcer with disoraganized epithelium, loss of cell attachment, signs of degeneration of the cells, many inflammatory cells $(\mathbf{1 . 1 2 0} \pm \mathbf{0 . 3 1 9})$ infilterate the granulation tissue and dilated blood vesselsand these results were in agreement with AZZA etal.,2012who reported that at 4 days post ulceration in immunosuppresed animal the area showed severe tissue reaction with massive infiltration of the thrombotic mass by polymorph nuclear cells, macrophages, and fibroblasts mixed with fibrin strands. No mitotic activity was observed.

In the present study, group III (treated with aftamed) histopathological findings of specimen stained with H\&E showed that there was decrease in ulcer size and the cells at the edge of epithelium showed mitotic activity also there was further migration of the epithelium into ulcer bed and there was inflammatory cells $(\mathbf{0 . 4 2 3} \pm \mathbf{0 . 1 2 3})$ infilteration and dilated blood vessels seen with in the granulation tissue after 7 days compared to untreated group $(\mathbf{0 . 6 0 4} \pm \mathbf{0 . 1 8 4})$.these findings were in agreement with Mahmoudetal.,2015 who reported that At 8 days postoperatively of using aftamed The full thickness of the keratinized epithelium at the incision area of palatal mucosa was fully restored, andThere was alsoa continued accumulation and fibroblastic proliferation in the underlying lamina propriaunderthe incision area. There were also Interlacing collagen fibers withinground substance density and invading blood capillaries were also obsereved. The inflammatory reaction was substantially diminished in the lamia propria.

In this study histological findings of section stained with H\&E showed that healing of oral ulcer in group III (with HA) was faster than healing in other groups which showed more organized re-epithelialization, significant decrease of inflammatory infilteration $(\mathbf{0 . 0 9 8} \pm \mathbf{0 . 0 3 1})$,compared with group II $(\mathbf{0 , 1 1 7} \pm \mathbf{0 . 0 2 9})$ neovascularization, early infilteration of fibroblast, and well organized collagen.

With the agreement with our result Al-Bayatyet al.,(2012) reported that In gel-treated group, the wound areas were smaller than that of the diabetic control group, and the granulation tissues from the gel-treated groups containedfewer inflammatory cells and more collagen and more proliferating blood capillaries than the granulation tissues of the diabetic control group. Aftamed stimulated and enhanced the deposition of collagen fibers and the formation of new blood vessels in the granulation tissue than the control treatment. 
In this work Ultra structure finding of MTX group at 4,7,14 days showed delayed regaining of epithelial cell to their attachment and wide intercellular space than Hyaluronic acid group (Aftamed)at 4, 7, 14 days which showed normal intercellular spaces with intact desmosomal junction during healing period.

These finding were in agreement with Fronza etal.,(2014) who reported that the wound treated with HYAL presented faster and higher re- epithelization compared to vehicle control group. After 5 and 7 days the wound closure in HYAL acid group reached 68\% (at day 5) and 89\% (at day 7) compared to control group, by day 14 the wounds of HYAL treatedgroup were completely closed in contrast with the wounds of control rats that were not completely healed.

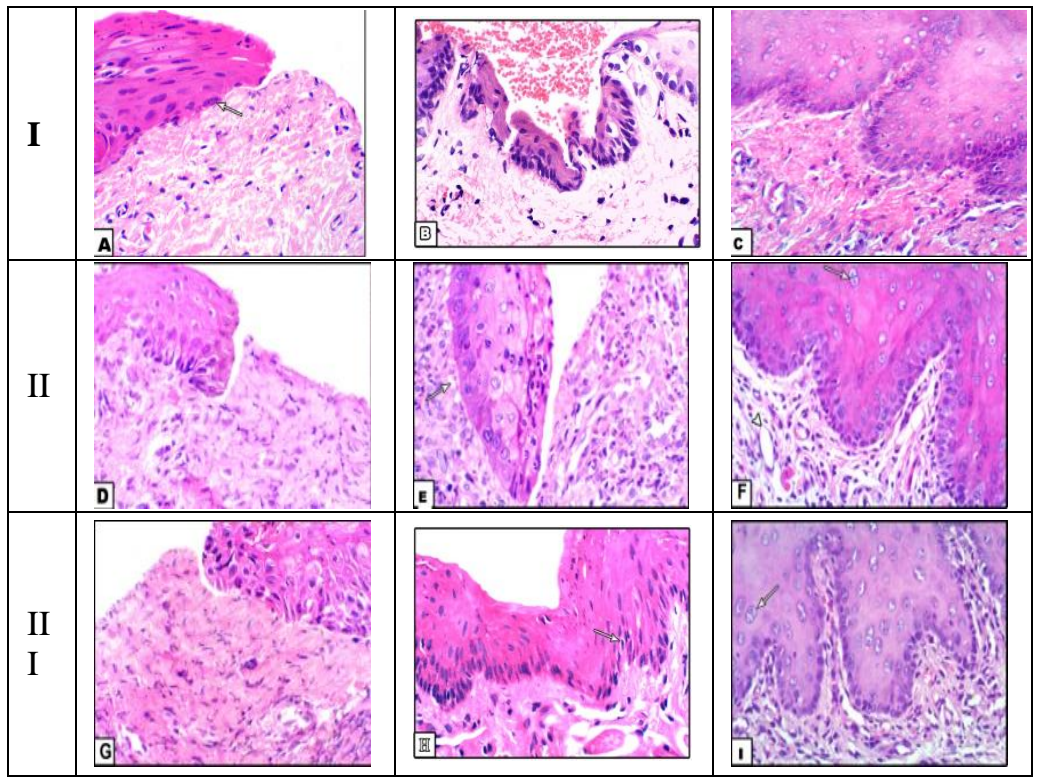

Fig 1: Photomicrograph of H\&E showing (A, B, C) group I,( D, E, F )group II( G, H, I )group III after 4, 7, 14 days respectively. (H\&E X 400)

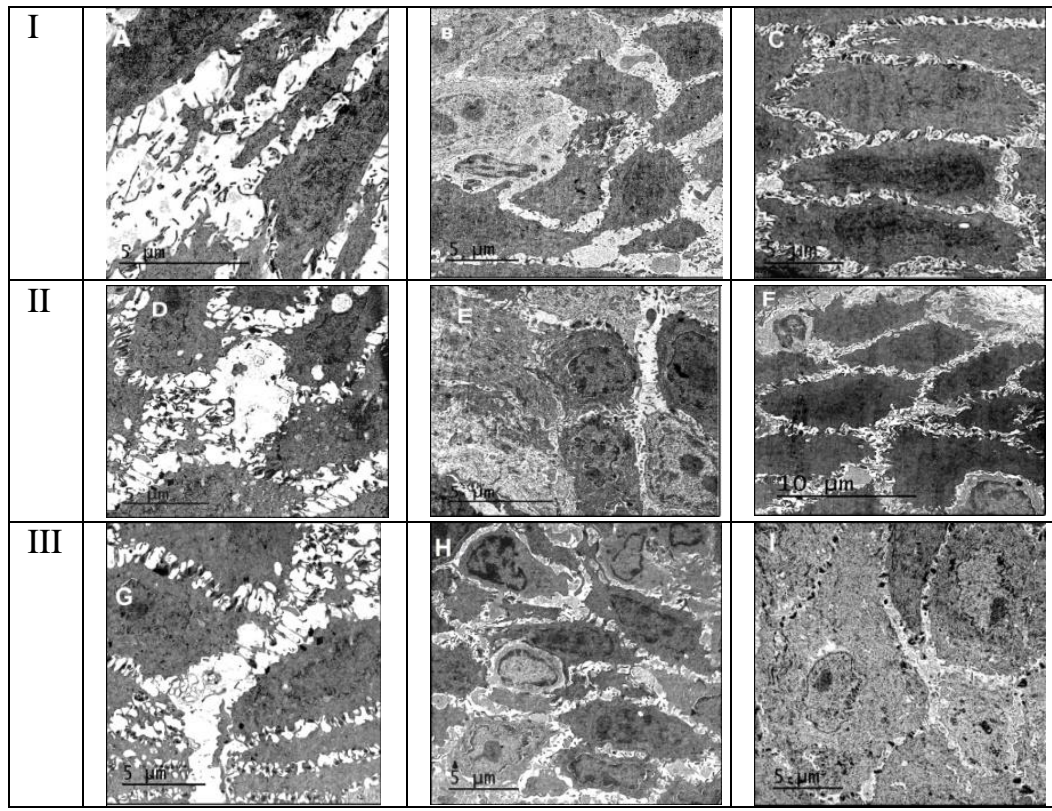

Fig 1: Photomicrograph of TEM showing A, B, C group I, D, E, F group II G, H, I group III after 4, 7, 14 days respectively.(X1500) 


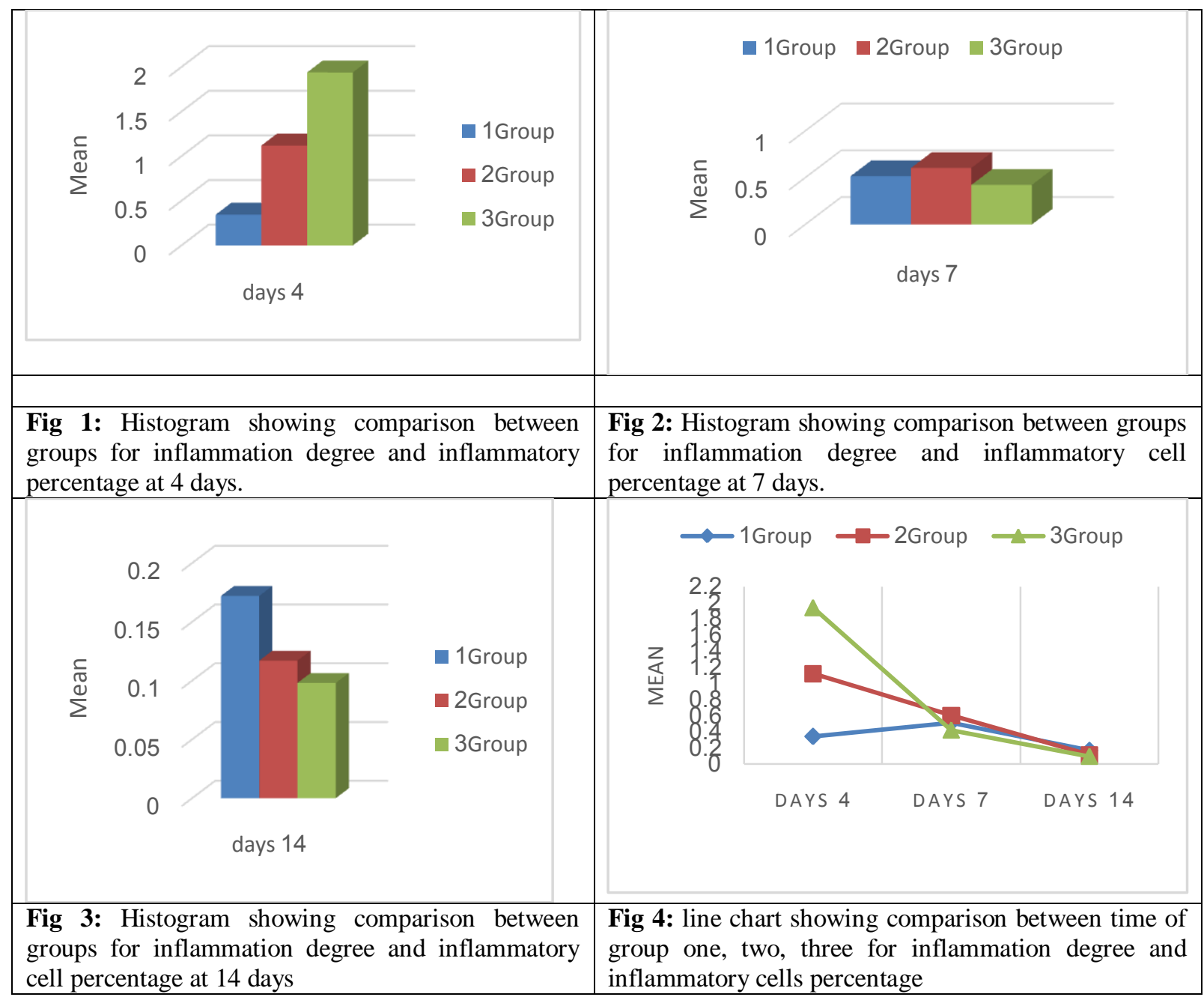

Table 1:-showing: one way ANOVA of comparison between groups for inflammation degree and inflammatory cells percentage.

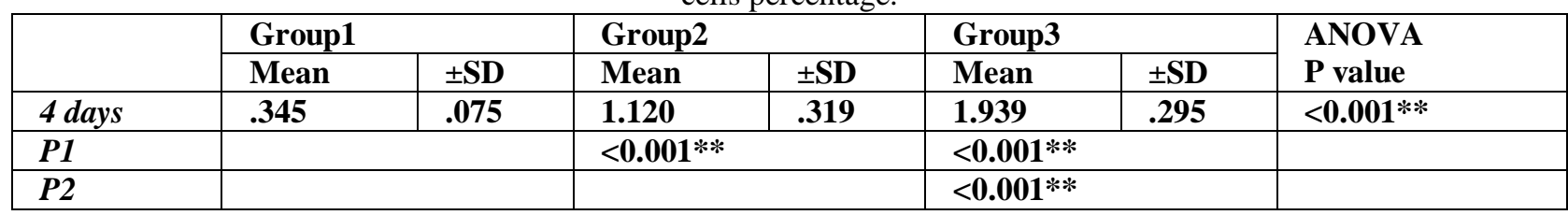

SD: standard deviation

*: significance $<0.05$

Test used: One way ANOVA followed by post-hoc tukey

P1: Significance between Group 1 and other groups

P2: Significance between Group 2 and Group 3

Table 2:-Showing one way ANOVA of comparison between groups for inflammation degree and inflammatory cell percentage.

\begin{tabular}{|c|c|c|c|c|c|c|c|}
\hline & \multicolumn{2}{|c|}{ Group1 } & \multicolumn{2}{|c|}{ Group2 } & \multicolumn{2}{|c|}{ Group3 } & \multirow{2}{*}{$\begin{array}{l}\text { ANOVA } \\
\text { P value }\end{array}$} \\
\hline & Mean & \pm SD & Mean & \pm SD & Mean & \pm SD & \\
\hline 7 days & .516 & .123 & .604 & .184 & .423 & .123 & 0.006* \\
\hline$P 1$ & & & 0.23 & & 0.2 & & \\
\hline$P 2$ & & & & & 0.004* & & \\
\hline
\end{tabular}


SD: standard deviation P:Probability

*: significance $<0.05 \quad$ **: high significance $<0.001$

Test used: One way ANOVA followed by post-hoc tukey

P1: Significance between Group 1 and other groups

P2: Significance between Group 2 and Group 3

Table 3:-Showing one way ANOVA of comparison between groups for inflammation degree and inflammatory cell percentage.

\begin{tabular}{|c|c|c|c|c|c|c|c|}
\hline & \multicolumn{2}{|c|}{ Group1 } & \multicolumn{2}{|c|}{ Group2 } & \multicolumn{2}{|c|}{ Group3 } & \multirow{2}{*}{$\begin{array}{l}\text { ANOVA } \\
\text { P value }\end{array}$} \\
\hline & Mean & \pm SD & Mean & \pm SD & Mean & $\pm \mathrm{SD}$ & \\
\hline 14 days & .172 & .049 & .117 & .029 & .098 & .031 & $<0.001 * *$ \\
\hline$P 1$ & & & 0.001* & & $<0.001$ & & \\
\hline$P 2$ & & & & & $\mathbf{0 . 3 3}$ & & \\
\hline
\end{tabular}

SD: standard deviation P:Probability

*: significance $<0.05 \quad$ **: significance $<0.001$

Test used: One way ANOVA followed by post-hoc tukey

P1: Significance between Group 1 and other groups

P2: Significance between Group 2 and Group 3

Table 4:-Showing one way ANOVA of comparison between time of group one for inflammation degree and inflammatory cell percentage.

\begin{tabular}{|c|c|c|c|c|c|c|c|}
\hline & \multicolumn{2}{|l|}{4 days } & \multicolumn{2}{|l|}{7 days } & \multicolumn{2}{|c|}{14 days } & \multirow{2}{*}{$\begin{array}{l}\text { ANOVA } \\
\text { P value }\end{array}$} \\
\hline & Mean & \pm SD & Mean & \pm SD & Mean & \pm SD & \\
\hline Group1 & .345 & .075 & .516 & .123 & .172 & .049 & $<\mathbf{0 . 0 0 1}$ \\
\hline$P 1$ & & & $<0.001$ & & $<0.001$ & & \\
\hline$P 2$ & & & & & $<0.001$ & & \\
\hline
\end{tabular}

SD: standard deviation P:Probability

*: significance $<0.05 \quad * *$ : significance $<0.001$

Test used: One way ANOVA followed by post-hoc tukey

P1: Significance between 4 days and other times

P2: Significance between 7 days and 14 days

Table 5:-Showing one way ANOVA of comparison between time of group two forinflammation degree and inflammatory cell percentage.

\begin{tabular}{|c|c|c|c|c|c|c|c|}
\hline \multirow[t]{2}{*}{ Group2 } & \multicolumn{2}{|l|}{4 days } & \multicolumn{2}{|l|}{7 days } & \multicolumn{2}{|c|}{14 days } & \multirow{2}{*}{$\begin{array}{l}\text { ANOVA } \\
\text { P value }\end{array}$} \\
\hline & Mean & $\pm \mathrm{SD}$ & Mean & $\pm \mathrm{SD}$ & Mean & $\pm \mathrm{SD}$ & \\
\hline & 1.120 & .319 & .604 & .184 & .117 & .029 & $<0.001$ \\
\hline$P 1$ & & & $<0.001$ & & $<0.001$ & & \\
\hline$P 2$ & & & & & $<0.001$ & & \\
\hline
\end{tabular}

SD: standard deviation P:Probability

*: significance $<0.05 \quad$ **: significance $<0.001$

Test used: One way ANOVA followed by post-hoc tukey

P1: Significance between 4 days and other times

P2: Significance between 7 days and 14 days

Table 5:-Showing one way ANOVA of comparison between time of group three for inflammation degree and inflammatory cell percentage.

\begin{tabular}{|c|c|c|c|c|c|c|c|}
\hline \multirow[t]{2}{*}{ Group3 } & \multicolumn{2}{|l|}{4 days } & \multicolumn{2}{|l|}{7 days } & \multicolumn{2}{|c|}{14 days } & \multirow{2}{*}{$\begin{array}{l}\text { ANOVA } \\
\text { P value }\end{array}$} \\
\hline & Mean & \pm SD & Mean & \pm SD & Mean & $\pm \mathrm{SD}$ & \\
\hline & 1.939 & .295 & .423 & .123 & .098 & .031 & $<0.001$ \\
\hline$P 1$ & & & $<0.001$ & & $<0.001$ & & \\
\hline$P 2$ & & & & & $<0.001$ & & \\
\hline
\end{tabular}

SD: standard deviation P:Probability

*: significance $<0.05 \quad$ **: significance $<0.001$

Test used: One way ANOVA followed by post-hoc tukey 


\section{P1: Significance between 4 days and other times}

P2: Significance between 7 days and 14 days

\section{Conclusion:-}

Based on the previous results we concluded that topically application of hyaluronic acid on oral ulcer on rats immunosuppressed by methotrexate lead to faster healing of the oral ulcer.

\section{References:-}

1. AlBayatyF,MahmoodA( 2012)A Comparison ofWound Healing Rate FollowingTreatment with Aftamed and Chlorine Dioxide Gels inStreptozotocin-Induced Diabetic Rats. Hindawi Publishing CorporationEvidenceBased Complementary and Alternative MedicineVolume, Article ID 468764,8pagesdoi:10.1155/2012/468764

2. AlRefai SA AL-Barazenchy AH, Khalil KA (2014) Immunohistochemical Study of the Effect of green Tea Extract on Methotrexate- Induced Oral Mucositis in Albino Rats. J cytolHistol, 5:3.

3. AzzA H.Metal.Histological Evaluation of low level laser Therapy (LLLT) on Oral Mucosal Wound Healing in Rabbit under Corticosteroid Therapy (2012) Med.J. Cairo Univ.,Vol. 80.No. 1. June:375-384..

4. Deeming, GMJ., Collingwood J, Pemberton MN (2005) British dental J. Vol 198 No. 2:22.

5.Fronza M et al (2014) Hyaluronidase Modulates Inflammatory Response and Accelerate the Cutaneous Wound Healing: open access. November Volume 9/ Issue 11/ e112297.

6.Kapoor P, sac deva S, and sac deva S (2011) Topical Hyaluronic acid in Themanagement of oral ulcers, Indian J Dermatol. 56(3):300-302.

7.Karavana SY (Hizarcioglu), Sezer B, Guneri P, Veral A, Boyacioglu H, Ertan G, Epstein JB (2011) .Efficacy of topical benzydamine hydrochloride gel on oral mucosa ulcers: an in vivo animal study. Int.J.OralMaxillofac.Surg. 40:973-978.

8.Maha Mahmoud et al(2015) Topical Surface Modifiers to Accelerate Healing and Re-epithelization Process in Vestibular/ Gingival Extension Surgical Procedure; Australian J of Basic ND applied Sciences 9(20) June , page:423-431 ISSN:1991-8178.

4.

9.Scully C, stephen R. Porter. Orofacial Disease (2003) Update for the Dental Clinical Team,comman Nonsystemic Causes of Oral Ulcers; 0443071845, 9780443071843.

10.Shaw TJ, Martin P (2009).Wound repair at a glance. J Cell Sci. 122(Pt 18):3209-3213. [PubMed: 19726630]. 